\title{
Modeling of asynchronous traction motor operation modes while turning locomotive wheelsets bandages
}

\author{
M.V. Kopanev \\ Automatics, telemechanics and communication department \\ Irkutsk state transport university \\ Irkutsk, Russian Federation \\ e-mail: mvk@irgups.ru
}

\author{
M.O. Arsentyev \\ Electric drive and electric department \\ Irkutsk national research technical university \\ Irkutsk, Russian Federation \\ e-mail: miha_ars@mail.ru
}

\begin{abstract}
At present special machines with built-in electric drives, including the electric drive of rotation of the wheelset, are used for turning the wheelset bandage without moving it from the locomotive. On the other hand, to move the locomotive to the turning point of the bandage, it is necessary to use an external power source of the asynchronous traction motor of the locomotive, since there is no contact network in the depot. Therefore, it is proposed to use the asynchronous traction motor of the locomotive to rotate the wheelset while turning the bandage. As an external power source of the asynchronous traction motor of a locomotive, a modern general-purpose frequency converter can be used. Modeling in the MatLab environment of the operation modes of a frequency electric drive with an asynchronous traction motor and a general industrial frequency converter has been carried out during turning of locomotive wheelsets. The obtained results can be useful for specialists of frequency electric drives based on common industrial converters in solving alternative control tasks.
\end{abstract}

Keywords - Asynchronous traction motor, modeling, frequency converter, turning, wheelset.

\section{INTRODUCTION}

In the process of the traction rolling stock operation, wear of the wheelset bandage takes place and the appearance of such defects as potholes, chips, sliders, etc. is possible. In addition to strengthening wheelset bandage of locomotives [1], the turning of the wheelset bandage without moving it from the locomotive [2] is of great importance.

On the market of technological equipment a wide selection of machines for turning wheel sets is presented. The most valuable machines were "A41". These machines are simple and reliable. Their disadvantage is that the turning process is performed by the operator manually. To rotate the wheelset in the design of the machine a rotation unit with an electric drive is used.

In the conditions of renewal of the fleet of traction rolling stock, their design changes. DC traction motors are replaced with asynchronous traction motors (for example, on locomotives 2ES5, 2TE25A). The problems associated with this process are discussed in detail in [3, 4, 5, 6, 7]. Thus, for these types of locomotives a power source, which allows the locomotive to move to the turning point (in the absence of a overhead contact system in the depot) is needed.

It is proposed to use the power source of the traction motor of the locomotive to rotate the wheelset during the turning process.

A functional diagram of a machine with an asynchronous traction motor for a wheelset rotation is shown in Figure 1.

The main technical characteristics of the asynchronous traction motor type AD-917UHL1, installed on the locomotive 2TE25A, are given in Table 1.

During the wheelsets turning, it is necessary to control the speed of the wheelset rotation from 30 to $60 \mathrm{rpm}$ and maintain a constant load torque on the motor shaft.

General industrial frequency converters allow to ensure smooth acceleration and braking of asynchronous motors, rotational speed control, maintaining the rated torque at a reduced speed, and can be used to solve the task, as shown in [8].

To assess the possibility of using an asynchronous traction motor of a locomotive with a general-purpose frequency converter for rotating a wheelset while turning a bandage, modeling of its operation modes in the MatLab environment was carried out. Similar models were obtained earlier in [9, $10]$.

\section{MODELING}

The model includes the Asynchronous Machine SI Units block, which simulates the processes taking place in the asynchronous traction motor. The load of the traction motor is simulated using the Constant and Step blocks. The AC Voltage Source blocks simulate the output parameters of a general-purpose frequency converter (voltage and frequency). To display the output parameters of the asynchronous traction motor (phase currents, speed, torque), the XY Graph and Scope blocks are used. The model is shown in Figure 2.

The calculation of the parameters of an asynchronous traction motor is made according to [1]. The results of the calculations are shown in Table 2. 


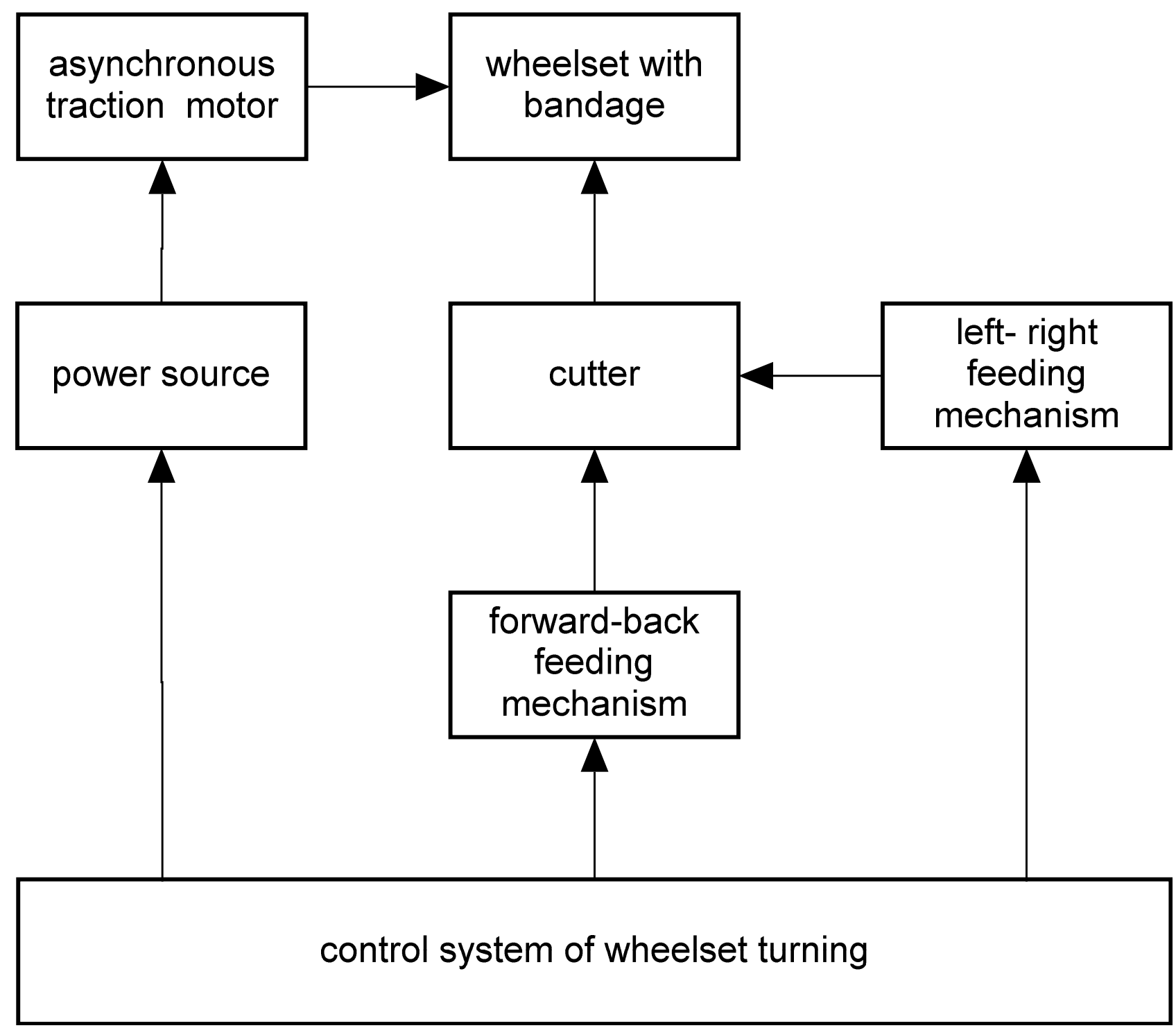

Fig. 1. Functional diagram

TABLE I. CHARACTERISTICS OF THE ASYNCHRONOUS TRACTION MOTOR

\begin{tabular}{|c|c|}
\hline Parameters & Nominal value \\
\hline Weight of electric motor, $\mathrm{kg}$ & 2250 \\
\hline Power, $\mathrm{kWt}$ & 470 \\
\hline Linear voltage, $\mathrm{V}$ & 710 \\
\hline Phase current, $\mathrm{A}$ & 485 \\
\hline Rotational speed, rpm & 425 \\
\hline Efficiency, $\%$ & 92.5 \\
\hline
\end{tabular}



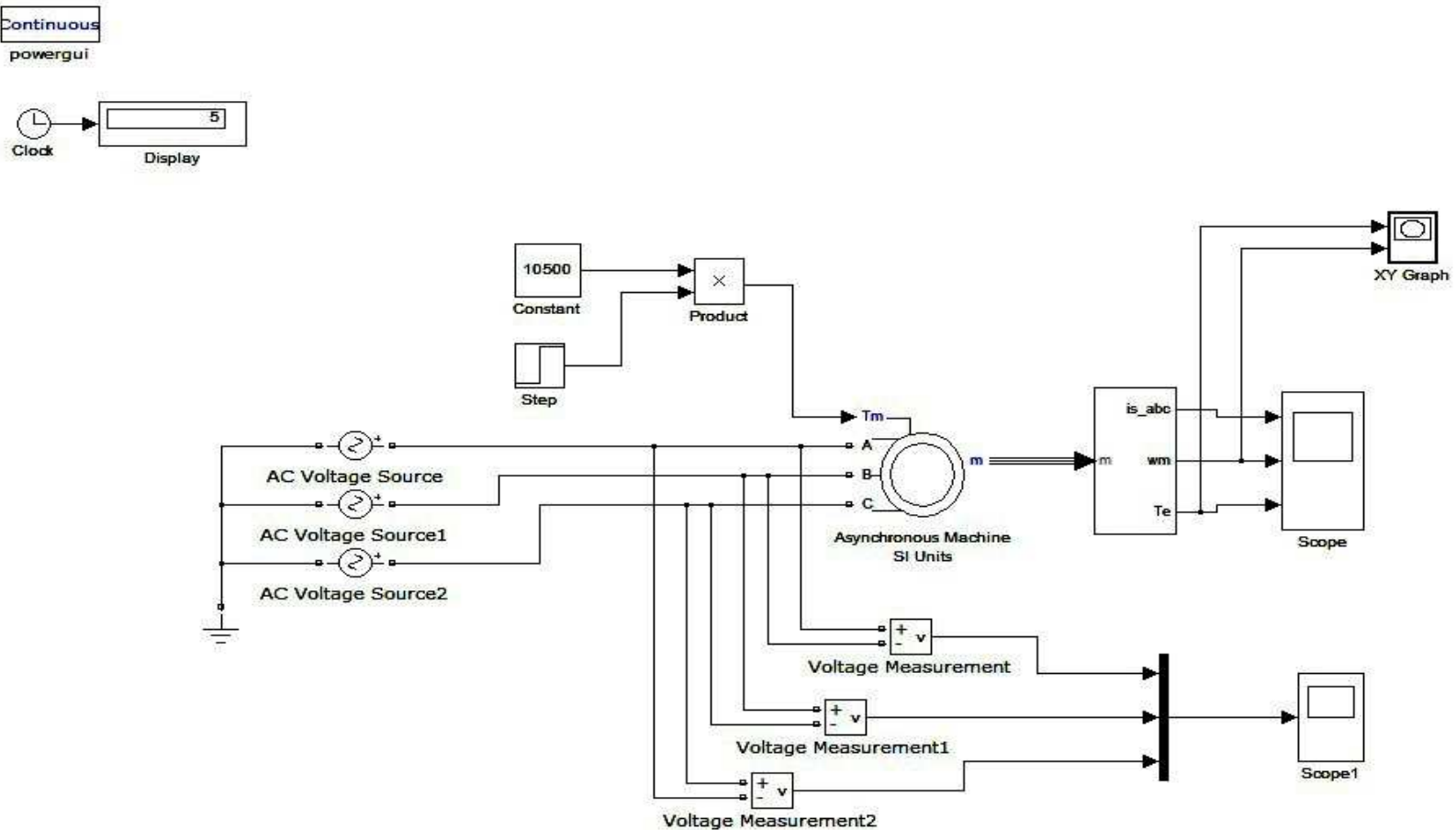

Fig. 2. The model in program MatLab

TABLE II. DESIGN PARAMETERS OF THE ASYNCHNONIC TRACTION MOTOR

\begin{tabular}{|c|c|c|c|}
\hline \multicolumn{2}{|c|}{ Description } & Value & Unit. measurements \\
\hline Nominal slip & $\mathrm{Sn}$ & 0.02968 & $\%$ \\
\hline Critical slip & $\mathrm{Sk}$ & 0.110769 & $\%$ \\
\hline Mechanical losses & $\Delta$ Pmech & 6351.351 & $\mathrm{~W}$ \\
\hline Stator resistance & $\mathrm{Rs}$ & 0.024335 & $\mathrm{H}$ \\
\hline Stator and rotor inductance & $\mathrm{L}$ & 0.0251511 & $\Omega$ \\
\hline Rotor Resistance & $\mathrm{Rr}$ & 0.055654 & $\mathrm{H}$ \\
\hline Stator and rotor leakage inductance & $\mathrm{Ll}$ & 0.000567 & $\mathrm{H}$ \\
\hline Mutual Induction & $\mathrm{Lm}$ & 0.020944 & $\mathrm{Nm} / \mathrm{s}$ \\
\hline Coefficient of viscous friction & $\mathrm{Bm}$ & 3.206499 & \\
\hline Constructive factor & $\mathrm{c} 1$ & 1.027056 & \\
\hline
\end{tabular}

Figure 3 shows the electromechanical characteristics of an asynchronous traction motor at rated parameters.

Figure 4 shows oscillograms of the current, speed and torque of an asynchronous traction motor at rated parameters.

In the course of the simulation, it is stated that at nominal startup parameters, the asynchronous traction motor accelerates in 1.25 seconds. The amplitude value of the noload current in the stator of the asynchronous traction motor is 196 A. The shaft rotational speed is $438.31 \mathrm{rpm}$, the torque value on the motor shaft is $149 \mathrm{Nm}$. In 3 seconds after starting, a load corresponding to the nominal value is applied to the motor. After a short transient process (about 0.7 seconds), the amplitude value of the current in the stator of the asynchronous traction motor increased to $644 \mathrm{~A}$. But the shaft rotational speed slightly decreases to a value of $411.57 \mathrm{rpm}$. The torque on the motor shaft under load is $10,671 \mathrm{Nm}$.

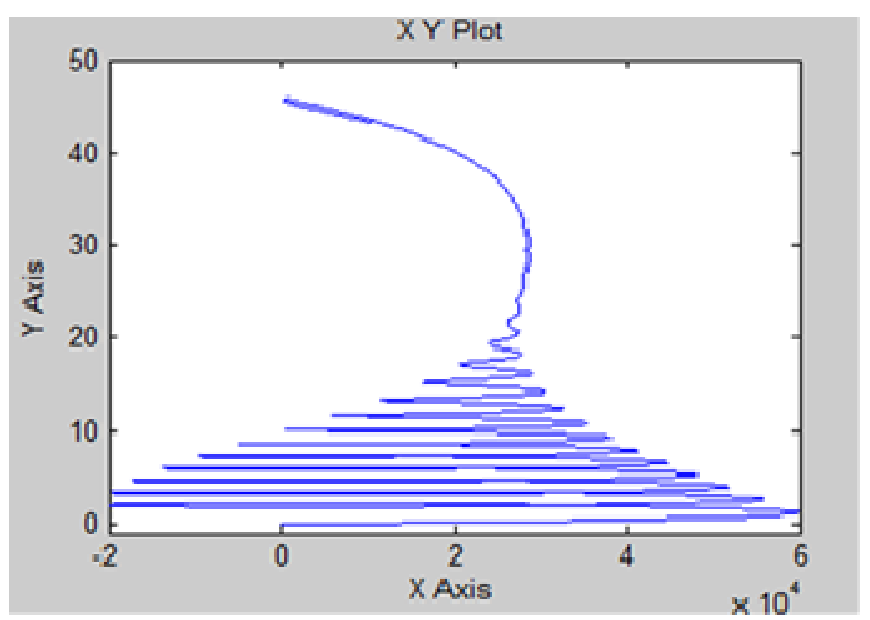

Fig. 3. The relationship between torque and speed 


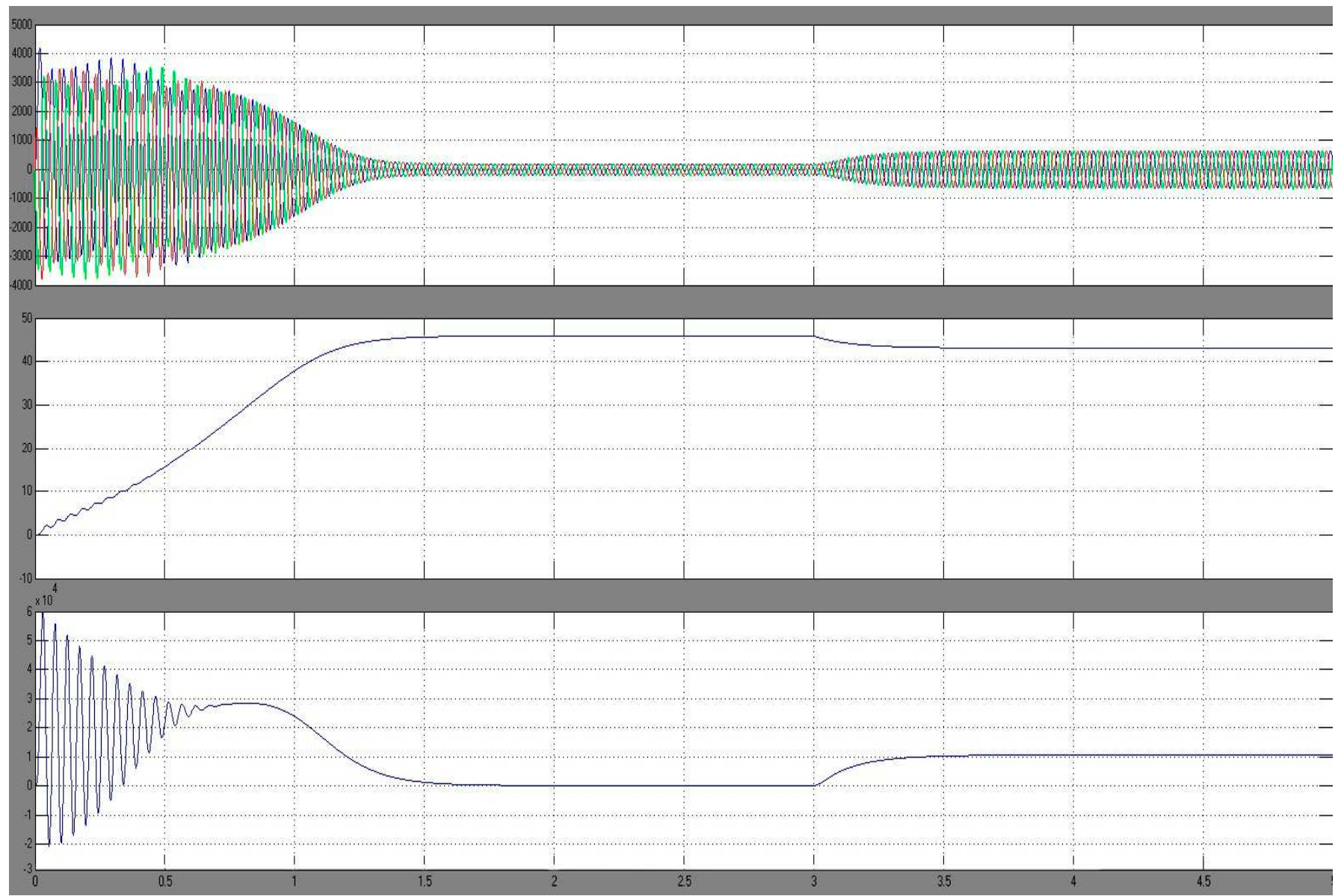

Fig. 4. Oscillograms of current, velocity and torque.

The obtained values (stator current, rotational speed, torque on the shaft) correspond to the specifications for an asynchronous traction motor. This testifies to the correct calculation of the parameters of the "Asynchronous Machine SI Units" block and it is possible to continue the investigation of the operation modes of the asynchronous traction motor together with the general industrial frequency converter.To provide a range of wheelset speed control from 30 to $60 \mathrm{rpm}$, the output frequency of the frequency converter varies in the range of $6-12 \mathrm{~Hz}$.

In order not to develop a special converter for an asynchronous traction motor having specific nominal values (in comparison with a standard asynchronous squirrel-cage motor), it is necessary to check the possibility of using a general industrial standard frequency converter with a power supply voltage of $380 \mathrm{~V}$ and a frequency of $50 \mathrm{~Hz}$.

To test this possibility, modeling of the operation modes of an asynchronous traction motor in two stages was performed.

At the first stage, the simulation was performed at the output voltage of the frequency converter supplied to the stator windings of the asynchronous traction motor (U) equal to 380 $\mathrm{V}$ and the output frequency (f) equal to $11.72 \mathrm{~Hz}$ (these output values should provide a wheelset speed of $60 \mathrm{rpm}$ ) at the load torque on the shaft corresponding to one created during the turning of the wheelsets, equal to $2,055 \mathrm{Nm}$.
Figure 5 shows the relationship between torque and speed.

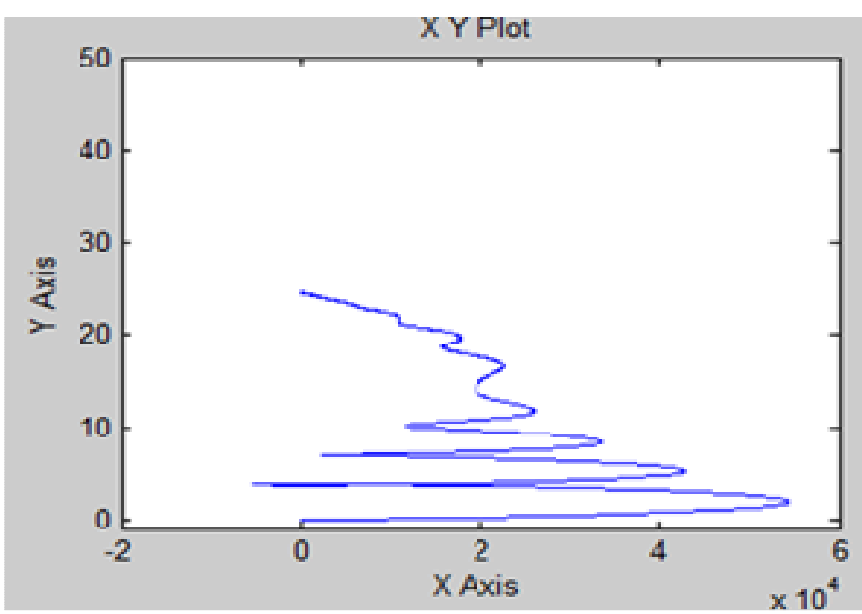

Fig. 5. The relationship between torque and speed

Figure 6 shows oscillograms of current, speed and torque. 


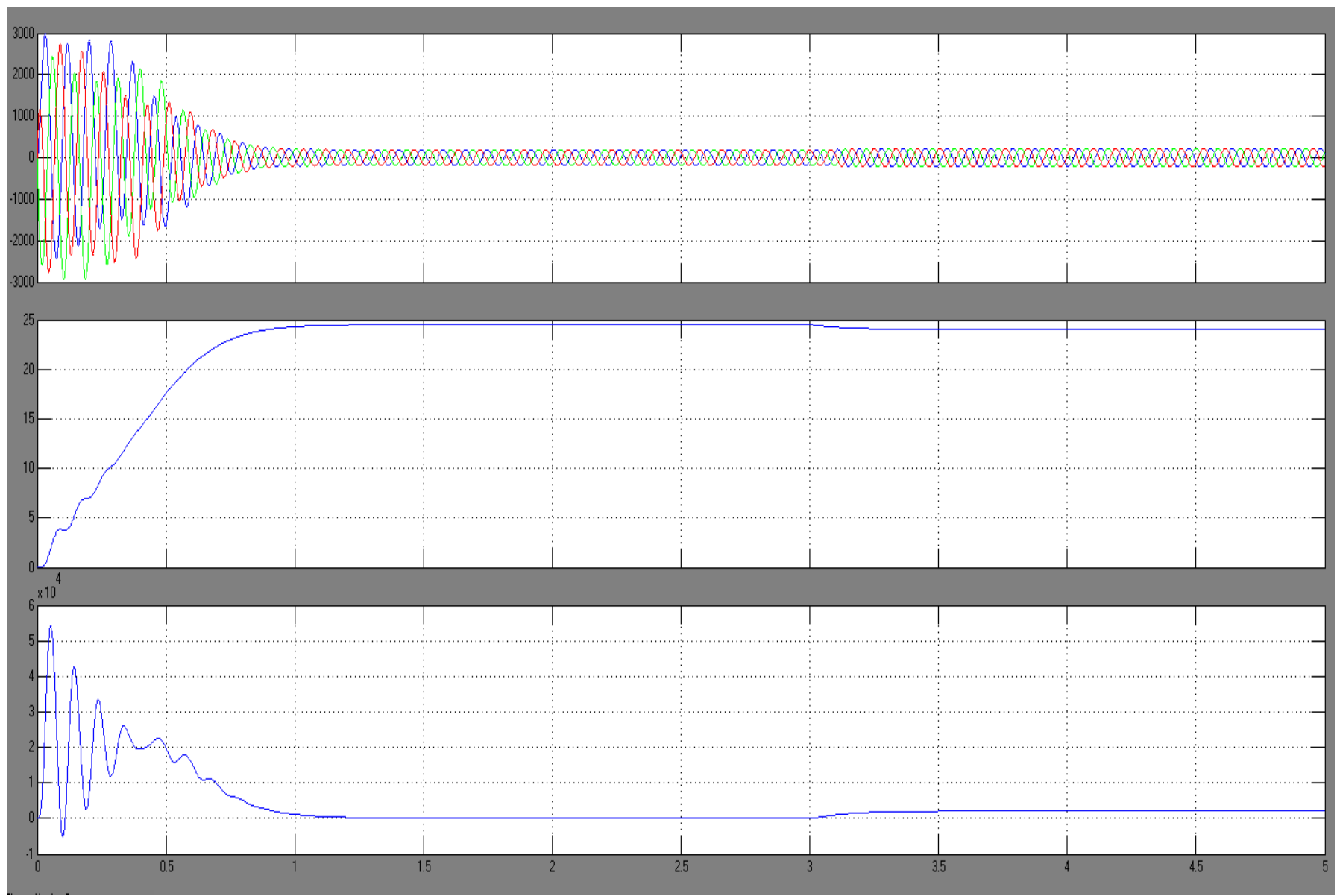

Fig. 6. Oscillograms of current, speed and torque

During the simulation it was established that at an output frequency of the converter $11.72 \mathrm{~Hz}$ and an output voltage of $380 \mathrm{~V}$, the amplitude value of the no-load current in the stator of the asynchronous traction motor is 228A (effective value $161.2 \mathrm{~A})$, the engine speed under load was $229.18 \mathrm{rpm}$ and corresponds to the wheelset speed of $62.79 \mathrm{rpm})$.

The next stage was modeling with the output voltage of the frequency converter supplied to the stator windings of an asynchronous traction motor equal to $172 \mathrm{~V}$ and an output frequency equal to $5.3 \mathrm{~Hz}$ (these output values should provide the rotational speed of the wheelset $30 \mathrm{rpm}$ ), the load torque on the motor shaft, corresponding to the one created during the turning of the wheelsets bandage is $2055 \mathrm{Nm}$.

Figure 7 shows the graph of the relationship between torque and speed.

Figure 8 shows oscillograms of current, speed and torque.

Thus, it was established that the amplitude value of the noload current in the stator of the asynchronous traction motor was 225A (effective value 159.2 A), and the rotational speed of the shaft under load was $101.22 \mathrm{rpm}$ (wheel speed 27.73 rpm respectively).

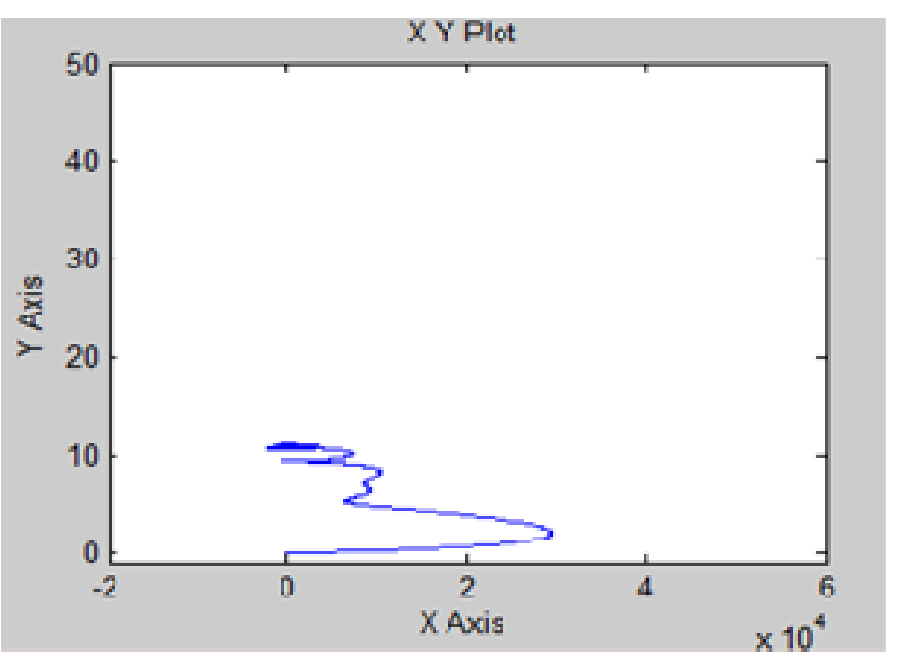

Fig. 7. The relationship between torque and speed 


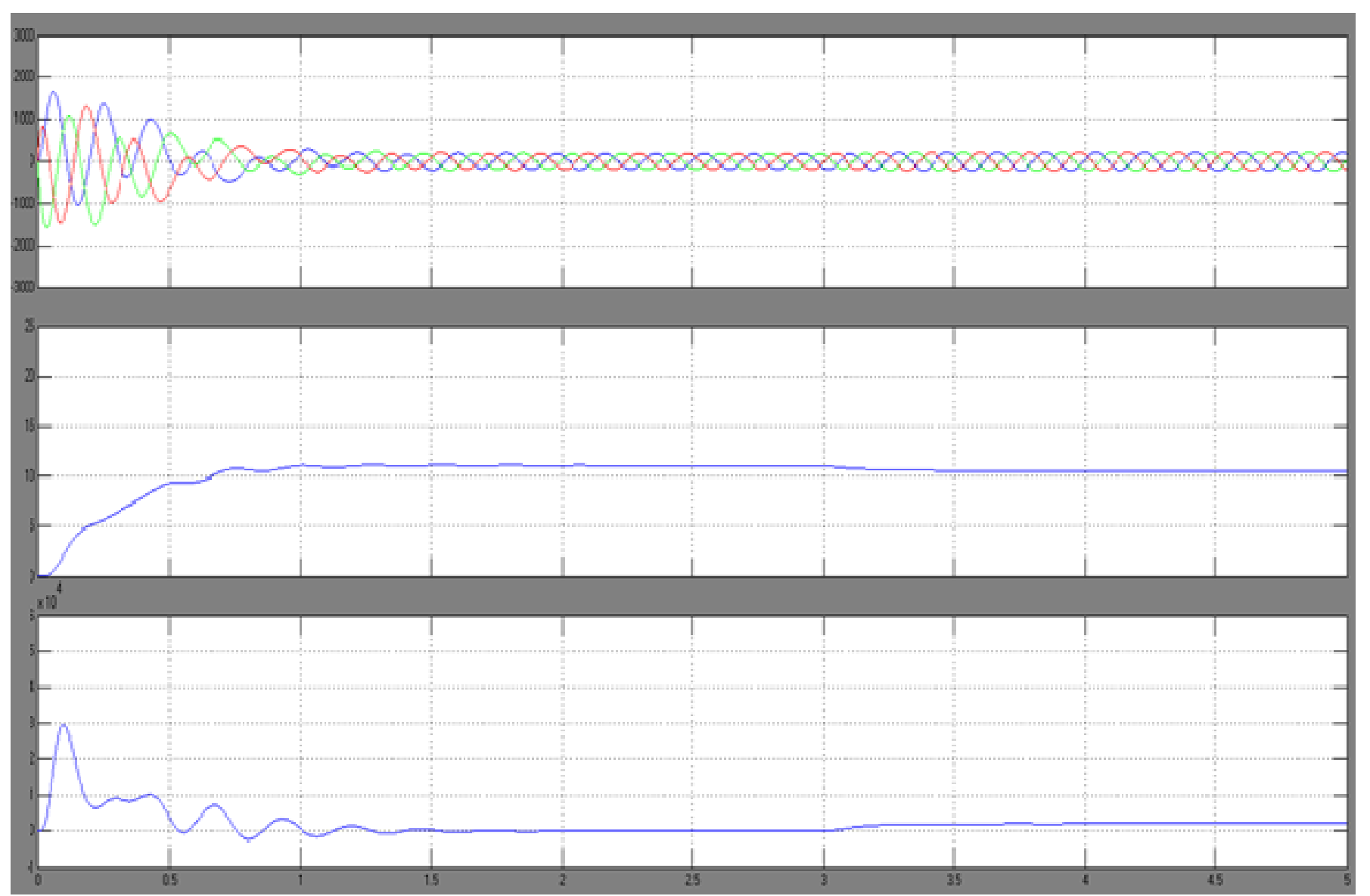

Fig. 8. Oscillograms of current, speed and torque

\section{CONCLUSION}

As a result of the simulation of a frequency electric drive with an asynchronous traction motor for turning the wheelsets and movement of the locomotive to the depot, it was established that in order to provide the required speed range of the wheelset $(30-60 \mathrm{rpm})$ with a constant load torque in the specified speed ranges, it is possible to use common industrial frequency converter. Simulation showed that to provide the required torque maintenance, the current in the stator of the asynchronous traction motor is not less than $160 \mathrm{~A}$, and respectively, as a power source for the movement of the locomotive to the point of turning in the depot (in the absence of a contact network) and rotation of the wheelset during the turning process a general industrial frequency converter with a power of at least $90 \mathrm{~kW}$ and a supply voltage of $380 \mathrm{~V}$ will be necessary. It will provide a long life of the system.

\section{References}

[1] A.A. Vorob'ev, A.V. Skrebkov, D.V. Osipov, "Evaluation of effectiveness of locomotives wheelsets bandages plasma strength on the East-Siberian railway," Bulletin of Ural State Transport University: scientific and technical journal, vol. 4, pp. 15-23, December 2011.
[2] A.P. Buynosov, I.V. Umylin, "Optimization of locomotives wheelsets bandages turning process," Scientific and technical Bulletin of Volga region, vol. 3, pp. 101-104, August 2015.

[3] V.A. Pivnev, A.G. German, V.M. Leont'ev, V.M. Chernigov, "Industrial tests of electric locomotives with asynchronous drive on United Kirovsky mine JSCo Apatit," Mine equipment and electrical engineering, vol. 3, pp. 37-38, April 2006.

[4] O.N. Zhulev, I.K. Ivanchenko, A.L. Kurochka, V.P. Yanov, "Problems of creation of electric locomotives with asynchronous traction motor," Higher educational institutes newsletters. Electrical engineering, vol. 11. - pp. 19-27, December 1983.

[5] N.A. Rotanov, A.S. Kurbasov, Yu.G. Bykov, V.V. Litovchenko, "Electric rolling stock with asynchronous traction motor," Transport, 1991.

[6] L.A. Muginshteyn, L.A. Kuchumov, O.N. Nazarov, "The choice of traction electric drive type," Railway transport, vol. 5, pp. 42-48, June 2005.

[7] A.I. Leshchev, K.P. Soltus, S.A. Usvitskiy, "Industrial electric locomotive NPM2 with asynchronous traction motor," Bulletin of the All-Russian Scientific Research and Design Institute of Electric Locomotive Building, vol. 1. pp. 118-125, February 2004.

[8] O.P. Mal'tseva, L.S. Udut, N.V. Koyain, "Systems of asynchronous frequency regulated electric drives control," Tomsk Polytechnic University, 2011.

[9] V.B. Terekhin, "Modelling of electric drive systems in Simulink," Tomsk Polytechnic University, 2010.

[10] Yu. A. Bakhvalov, A. A. Zarif'yan, P. G. Kolpakhch'yan, "Modelling of electric locomotive electromechanical system with asynchronous traction drive," Transport, 2001. 